\title{
Alexandra Heidle, Jan A. M. Snoek (éd.), Women's Agency and Rituals in Mixed and Female Masonic Orders
}

Leyden-Boston, Brill, 2008, 436 p.

Jean-Louis Ormières

\section{OpenEdition \\ Journals}

Édition électronique

URL : http://journals.openedition.org/assr/23500

DOI : $10.4000 /$ assr.23500

ISSN : $1777-5825$

Éditeur

Éditions de l'EHESS

Édition imprimée

Date de publication : 31 décembre 2011

Pagination : 174

ISBN : 9782713223273

ISSN : 0335-5985

\section{Référence électronique}

Jean-Louis Ormières, « Alexandra Heidle, Jan A. M. Snoek (éd.), Women's Agency and Rituals in Mixed and Female Masonic Orders ", Archives de sciences sociales des religions [En ligne], 156 | octobredécembre 2011, document 156-52, mis en ligne le 15 février 2012, consulté le 21 septembre 2020. URL : http://journals.openedition.org/assr/23500 ; DOI : https://doi.org/10.4000/assr.23500 


\title{
Alexandra Heidle, Jan A. M. Snoek (éd.), Women's Agency and Rituals in Mixed and Female Masonic Orders
}

Leyden-Boston, Brill, 2008, 436 p.

\author{
Jean-Louis Ormières
}

\section{RÉFÉRENCE}

Alexandra Heidle, Jan A. M. Snoek (éd.), Women's Agency and Rituals in Mixed and Female Masonic Orders, Leyden-Boston, Brill, 2008, 436 p.

1 S'appuyant sur les approches et les travaux les plus récents, cet ouvrage collectif qui traite des relations entre les femmes et la franc-maçonnerie tourne principalement autour de deux aspects interdépendants, le pouvoir que les femmes ont pu y exercer et leur influence dans l'évolution du rituel. Fondées avant tout sur des documents de première main, ces dix contributions se singularisent par le fait qu'elles concernent non pas uniquement le XVIII ${ }^{\mathrm{e}}$ siècle, comme c'était le plus souvent le cas jusque-là, mais aussi le XIX ${ }^{e}$ siècle, celui de la première vague du mouvement féministe.

2 Si la franc-maçonnerie dont l'origine est anglaise est longtemps demeurée un phénomène exclusivement masculin, on doit néanmoins souligner que c'est dans les loges maçonniques de France que l'on trouve mention, dés les années 1740, d'initiations de femmes. Dans le même temps, un assez grand nombre d'ordres mixtes furent créés. Certes, il ne s'agissait pas à proprement dit d'ordres maçonniques, mais de "sociétés " d'inspiration maçonnique. C'est notamment le cas de l'Ordre des Hermites de bonne humeur créé par la duchesse de Saxe-Gotha, Louise Dorothea (contribution de Bärbel Raschke). Comprenant hommes et femmes du monde aristocratique, cette société ouvrit la voie aux nombreuses loges dites «d'adoption» qui furent toutefois moins 
nombreuses en Allemagne qu'en France où, dès 1774, le Grand Orient de France les reconnut officiellement. C'est une de ces loges d'adoption, La Loge de Juste, que décrit et analyse Malcom Davies. Créée en janvier 1751, par des hommes, la loge ouvrit moins de six mois plus tard ses portes aux femmes. Les archives de cette loge dont les membres appartenaient soit à la noblesse, soit aux acteurs et actrices de la ComédieFrançaise renferment, à ce jour, le plus ancien document manuscrit concernant le rituel d'une loge d'adoption.

3 Andreas Önnerfors rappelle qu'après la révolution de 1789, ces loges d'adoption, ainsi que l'ensemble de la franc-maçonnerie, s'embourgeoisent. Elle affirme par ailleurs qu'en dépit de leur subordination au Grand Orient de France, loge exclusivement masculine, et contrairement à ce qu'on a pu penser jusque-là, ces loges mixtes peuvent être considérées comme des lieux d'émancipation des femmes "avant la lettre " (Andreas Önnerfors).

4 Reste, comme le montre James Smith Allen, que le véritable moment de la " coïncidence » entre la réforme maçonnique et le mouvement des Femmes en France est la période 1840-1940. La lutte des femmes pour intégrer les loges maçonniques ne peut être détachée du contexte général de leur combat pour l'égalité politique des deux sexes. Les origines de la progression de la maçonnerie mixte en France, écrit Allen, résident dans la remarquable synergie des hommes et des féministes qui œuvrèrent ensemble au nom des intérêts des femmes, non seulement dans la franc-maçonnerie, mais partout.

5 Mais, dans d'autres pays que la France, le développement historique du féminisme eut une incidence notable sur l'évolution de la franc-maçonnerie. En Hollande, souligne Anton Van de Sande, les conséquences de cette influence furent au moins discutées sinon prises en compte dans les loges tout au long de la deuxième moitié du XIX siècle. De même, si, en Angleterre, le mouvement féministe n'a guère modifié le courant dominant "régulier » de la franc-maçonnerie, cela ne signifie nullement qu'il n'a eu aucune incidence, comme le démontre Henrik Bogdan. En effet, nombre des ordres mixtes qui $\mathrm{y}$ furent fondés à la fin du $\mathrm{xIx}^{\mathrm{e}}$ siècle avaient sous une forme ou sous une autre partie liée ou s'inspiraient de la franc-maçonnerie. C'est notamment le cas de la société occultiste Golden Dawn qui, sans se référer explicitement à la maçonnerie, fut néanmoins créée par trois francs-maçons qui avaient accueilli des femmes, celles-ci y étaient traitées sur un pied d'égalité avec les hommes faisant ainsi honneur aux revendications féministes du temps. La contribution de Bernard Dat est consacrée à la maçonnerie "opérative» de Clement Edwin Stretton (1850-1915) et ne fait que confirmer cette incidence du mouvement féministe. À partir de 1910, Stretton ouvrit en effet son ordre aux Ladies.

Cependant l'ordre mixte le plus influent et le plus important, qui s'est d'abord épanoui en France avant de s'étendre en Angleterre, est sans conteste « Le Droit Humain ». C'est d'ailleurs un des leaders de cet ordre, qui joua un rôle important dans l'organisation de la manifestation du 17 juin 1911, que s'attache à décrire Ann Pilcher Dayton dans sa contribution sur la franc-maçonnerie et la question du suffrage féminin. Fruit du concours de trois approches, celle de la théosophie, de la franc-maçonnerie et du mouvement des suffragettes, cette manifestation, la plus importante, avait axé ses revendications sur deux principes : le développement du progrès individuel spirituel et l'égalité. Le soutien de la cause des suffragettes explique l'attrait des femmes pour cet ordre. 
7 Andrew Prescott nous livre une vue d'ensemble des activités maçonniques de la célèbre et charismatique Annie Besant (1847-1933) en montrant que ses multiples engagements et responsabilités (activiste socialiste, présidente de la société théosophique, première présidente de l'Indian National Congress, etc.) avaient tous pour but ultime l'amélioration de la condition et de la situation de la femme.

8 C'est en définitive au lendemain de la Seconde Guerre mondiale qu'apparaissent les ordres uniquement féminins précédant de deux décennies la seconde vague féministe des années soixante. En France, les femmes présentes dans les anciennes loges d'adoption quittent celles-ci pour créer le 21 octobre 1945 un ordre séparé des hommes, "l'Union Maçonnique Féminine de France ». L'adoption d'un rite différent suscita des scissions, certaines femmes préférant revenir aux rituels d'initiation traditionnels comme en Hollande ou en Allemagne.

9 Les anciens ordres mixtes n'ont pas pour autant disparu, comme le montre l'étude d'Anne van Marion-Weijer sur les développements récents de la Fédération hollandaise du Droit Humain qui se singularise par la cohabitation de trois traditions en matière de rituel, hollandais (sagesse, force et beauté), français (liberté, égalité, fraternité) et anglais (foi, espoir et charité).

10 S'il reste encore beaucoup à découvrir sur les femmes et la franc-maçonnerie, on manque notamment de journaux écrits ou de discours prononcés par des femmes franc-maçonnes permettant une meilleure appréhension de leurs émotions ou de leurs sentiments, cet ouvrage apporte des éléments importants et indispensables à toute recherche centrée sur cette question et plus généralement sur l'évolution de la condition féminine et des mentalités.

11 Bien que Jan A. M. Snoek ait pris soin de faire remarquer dans son introduction qu'il existe des ordres mixtes ou uniquement féminins dans plusieurs autres pays non mentionnés dans cet ouvrage et que le but n'était pas l'exhaustivité, mais d'appréhender la manière dont les femmes avaient participé aux ordres maçonniques, on peut regretter que l'étude n'ait pas englobé un ou deux pays «émergents » où les ordres sont aujourd'hui présents. 